Título do Trabalho

\title{
RESTAURAÇÃO FLORESTAL NAS ÁREAS DE PRESERVAÇÃO PERMANENTE DO CÓRREGO DO GALANTE (MONTE CASTELO E TUPI PAULISTA, SP) POR MEIO DE PROGRAMA DE FOMENTO FLORESTAL.
}

Nome do Autor Principal

Jorge Watanabe

Nome do Co-autor

Carlos José Rodrigues

Empresa

\section{CESP- Companhia Energética de São Paulo}

E-mail de contato

Jorge.watanabe@cesp.com.br

Resumo: O programa de reflorestamento desenvolvido pela CESP é implantado por meio de estratégias diferenciadas. São realizados reflorestamentos em áreas de propriedade da empresa, junto à borda dos reservatórios, compreendidas entre as cotas normal de operação e de desapropriação e, fora da cota de desapropriação, junto à propriedades rurais localizadas na área de influência dos reservatórios da empresa, por meio de um programa de fomento florestal. Este trabalho tem como objetivo relatar o caso da parceria constituída entre proprietários rurais da microbacia do Córrego do Galante, Ministério Público Estadual e CESP para restauração da mata ciliar da Área de Preservação Permanente do córrego, por meio do Programa de Fomento Florestal, o qual se constitui numa cooperação recíproca, onde a CESP, após a análise técnica da solicitação do interessado, fornece o projeto técnico executivo, a orientação técnica para implantação e as mudas das espécies necessárias, e o proprietário fornece a mão de obra e os insumos básicos requeridos para implantação do reflorestamento. Houve adesão de 52 proprietários rurais cujas Áreas de Preservação Permanente a serem restauradas variaram de 0,18 a 7,67 hectares, totalizando 57,04 hectares, que correspondeu ao plantio de 114 mil mudas. Em monitoramento realizado em junho de 2010 constatou-se que dos 52 contratos de cooperação, 36 projetos apresentam reflorestamentos bem formados, totalizando 26,67 hectares (46,7\% do total previsto), oito projetos estão parcialmente formados, 
abrangendo 12,14 hectares (21,3\%) e oito projetos ainda não estão formados, envolvendo 18,23 hectares $(32,0 \%)$. Os proprietários cujos projetos não se desenvolveram são intimados pela Promotoria para regularização.

PALAVRAS CHAVE- Fomento Florestal. Mata Ciliar. Área de Preservação Permanente.

\section{INTRODUÇÃO}

A formação dos reservatórios da CESP na bacia do Alto Paraná (UHE's Engenheiro Souza Dias, Três Irmãos, llha Solteira e Engenheiro Sérgio Motta) submergiu remanescentes de importantes formações vegetais como as Savanas (cerrado e cerradão), características dos estados de Minas Gerais, Goiás e Mato Grosso do Sul, a Floresta Estacional Semidecidual Submontana, de ocorrência especialmente no estado de São Paulo, e, principalmente, os campos de várzeas e a Floresta Estacional Semidecidual Aluvial (mata ciliar), presente em todas as regiões de influência daqueles reservatórios.

Devido aos impactos da formação dos reservatórios sobre as matas ciliares e os organismos que nelas e delas vivem, e às exigências da legislação ambiental vigente, a CESP tem o compromisso de recomposição dessas matas, seja com objetivos utilitários (controle hidrológico, com manutenção da disponibilidade e qualidade da água, que é a matéria prima para a geração hidroelétrica, evitando problemas operacionais como a redução do volume útil dos reservatórios pelo assoreamento, e o desgaste de equipamentos das usinas devido à abrasão por sólidos em suspensão) ou de conservação (restabelecimento da estrutura e dinâmica das comunidades florestais, através de fenômenos como sucessão ecológica, diversidade de espécies, reciclagem de nutrientes, conectividade da paisagem e fluxo gênico).

A recomposição de matas ciliares desenvolvidas pela Companhia visa à proteção dos solos e dos recursos hídricos nas áreas de drenagem dos reservatórios, a conservação de espécies vegetais e animais e a manutenção da diversidade genética nas áreas de influência dos reservatórios (CESP, 1992). Possibilita também 0 restabelecimento da estrutura e dinâmica das comunidades florestais, por meio de fenômenos como sucessão ecológica, biodiversidade, fluxo gênico, ciclagem de 


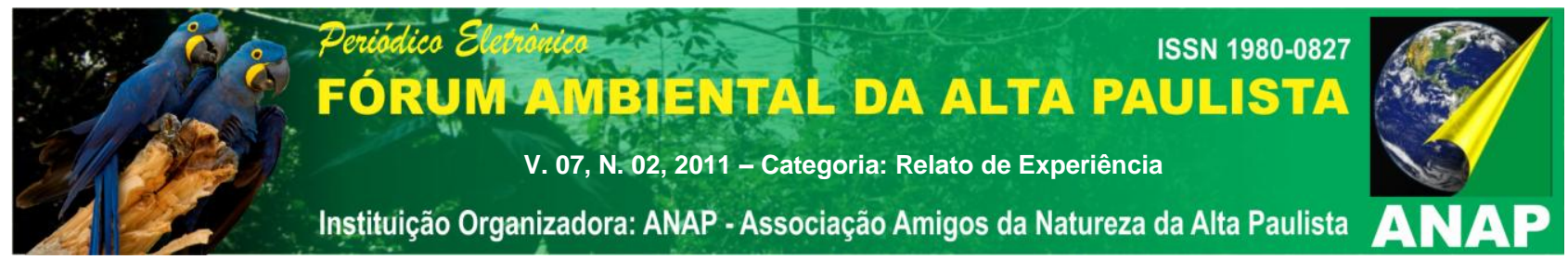

nutrientes, produção primária etc. (KAGEYAMA et al., 1992). O reflorestamento, a partir de técnicas adequadas de coletas de sementes e produção de mudas, possibilita a conservação in situ das diversas espécies utilizadas (KAGEYAMA \& CASTRO, 1988) e, conseqüentemente, sua evolução contínua em ecossistemas quer vem sendo modificados. (MARTINS, 1988)

O programa de reflorestamento é desenvolvido por meio de estratégias de atuação diferenciadas: reflorestamento em áreas de propriedade da CESP, junto às bordas dos reservatórios, compreendidas entre as cotas normal de operação e de desapropriação e, fora das cotas de desapropriação, junto à propriedades rurais localizadas nas áreas de influência dos reservatórios, por meio de um programa de fomento florestal.

A restauração das áreas de preservação permanente com o plantio de árvores nativas depende em grande medida do produtor rural, que irá plantar e cuidar das mudas. Portanto, para o sucesso de programas de fomento florestal, é fundamental considerar e conhecer o perfil dos produtores e suas relações com a árvore e a floresta.

O componente ambiental não poderá estar separado do social e do econômico, para a implantação de mata ciliar nas margens dos cursos d água, é preciso conhecer a cultura das pessoas que vivem nestas áreas e suas necessidades.

A avaliação dos entraves sociais e econômicos para a restauração das áreas de preservação permanente (APPs) nos limites legais é necessária para a formulação de uma política pública consistente, pois a degradação e a perda de solo contribuem significativamente para o agravamento da pobreza no meio rural. Quando as áreas a serem restauradas estão situadas dentro de pequenas propriedades rurais, as questões de ordem econômicas passam a ter maior relevância, pois se referem aos espaços já ocupados por alguma atividade econômica que provê sustento às famílias dos agricultores.

A principal característica socioeconômica das propriedades da microbacia do Córrego do Galante reside no predomínio da agricultura familiar, aquela em que o envolvimento dos membros da família nas tarefas agrícolas é elevado.

Contemporaneamente tem sido extremamente desafiadora para a agricultura familiar a necessidade de conjugar sustentabilidade econômica e ambiental. 


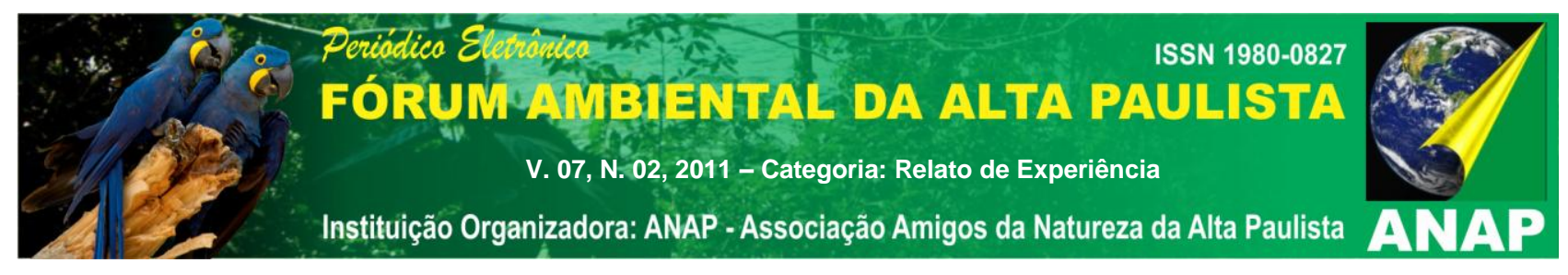

\section{OBJETIVO GERAL}

Analisar a implantação de reflorestamento ciliar de áreas de preservação permanente (APPs) em 52 propriedades banhadas pelo Córrego do Galante, nos municípios de Tupi Paulista e Monte Castelo, e a visão dos produtores sobre o processo.

\section{METODOLOGIA.}

O local de estudo é a microbacia do córrego do Galante que abrange dois municípios da Região Alta Paulista, o córrego tem sua nascente em Tupi Paulista e deságua no rio Aguapeí, nos limites do Parque Estadual do Aguapeí, município de Monte Castelo (Figura 1).

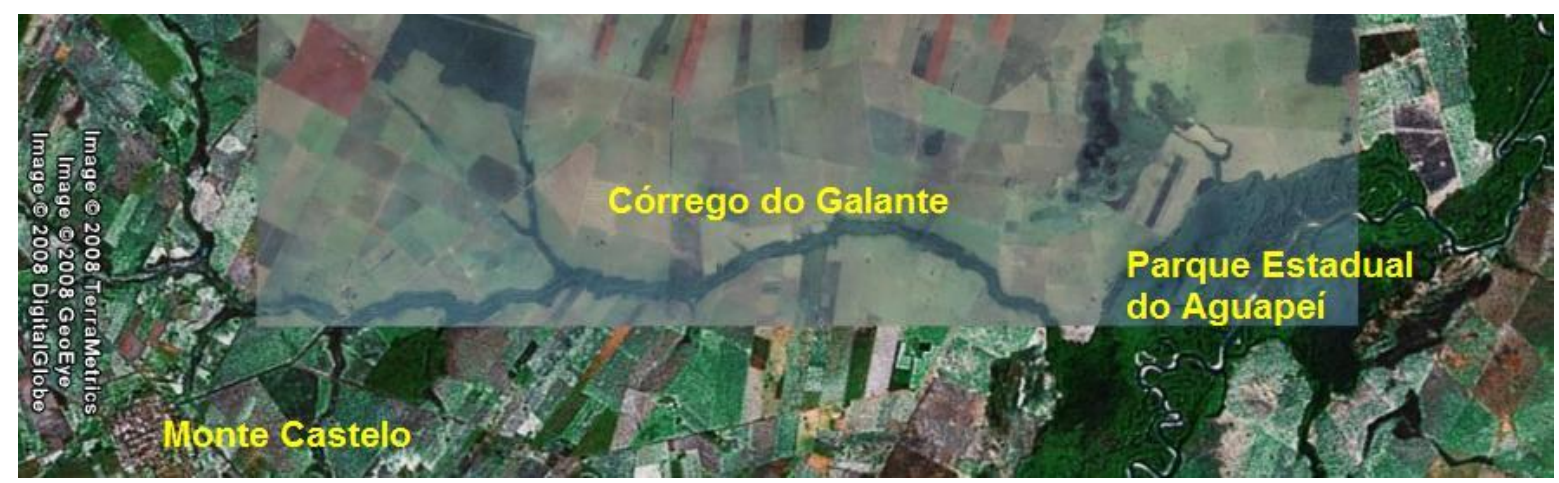

Figura 1. Microbacia do Córrego do Galante (fonte: Google Earth).

O sistema no qual se insere o córrego é de extrema importância para o sustento de diversas atividades econômicas, infelizmente, e em decorrência de ações antrópicas tais como uso e ocupação inadequada do solo, desmatamento, lançamento de esgotos sanitários "in natura", tem-se verificado que o córrego do Galante vem sofrendo diversos impactos ambientais, o que promove níveis altos de degradação ao longo do seu curso. 


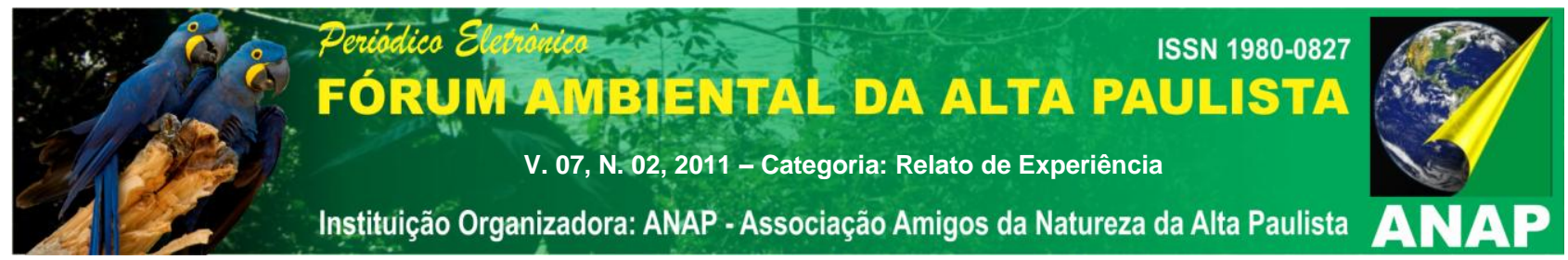

O desenvolvimento do Programa de Fomento Florestal na microbacia do córrego do Galante teve início com a solicitação, formalizada em 20 de dezembro 2006, pela Prefeitura Municipal de Monte Castelo, SP, do apoio da CESP aos produtores rurais que haviam sido notificados pela Promotoria de Justiça de Tupi Paulista a restaurar a vegetação ciliar nas suas propriedades. Posteriormente, em 10 de janeiro de 2007 foi realizada, com o apoio da Prefeitura, uma reunião com todos os interessados, ocasião em que os técnicos da CESP prestaram informações sobre o programa e esclareceram as obrigações de cada uma das partes. Naquela ocasião foram fornecidas as fichas de adesão, as quais foram preenchidas pelos interessados e remetidas à CESP.

Após análise das fichas de adesão, os técnicos da CESP agendaram visitas às propriedades dos interessados a fim de coletar os dados técnicos necessários à elaboração dos projetos de reflorestamento.

Houve adesão de 52 proprietários rurais cujas Áreas de Preservação Permanentes a serem restauradas variam de 0,18 a 7,67 hectares, totalizando 57,04 hectares, que correspondeu ao plantio de 114 mil mudas. São nove proprietários de Tupi Paulista, cuja área total é de 8,37 hectares, e 43 proprietários de Monte Castelo, cuja área total é de 48,67 hectares.

\section{RESULTADOS}

Em monitoramento realizado em julho de 2010 constatou-se que dos 52 contratos de cooperação, 36 projetos foram implantados com reflorestamentos bem formados, totalizando 26,67 hectares ( $46,7 \%$ do total previsto), oito projetos estão parcialmente formados, abrangendo 12,14 hectares $(21,3 \%)$ e oito projetos ainda não estão formados, envolvendo 18,23 hectares (32,0\%), conforme exemplificado na Figura 2. Os proprietários cujos projetos não estão se desenvolvendo satisfatoriamente são intimados pelo Ministério Público para a devida regularização. 


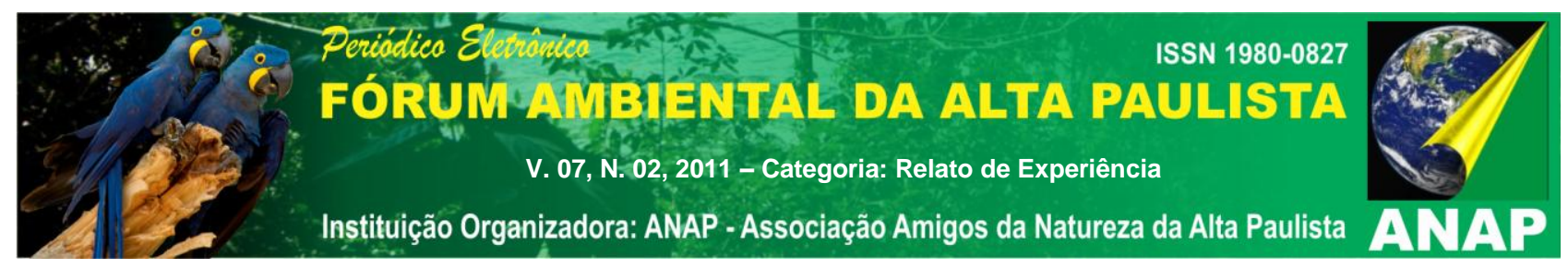

Para muitos proprietários a implantação da mata ciliar em suas propriedades foi benéfica, tendo como principais indicadores a volta da fauna, como pássaros e pequenos mamíferos, e a melhoria da qualidade da água do córrego, com maior presença de peixes.

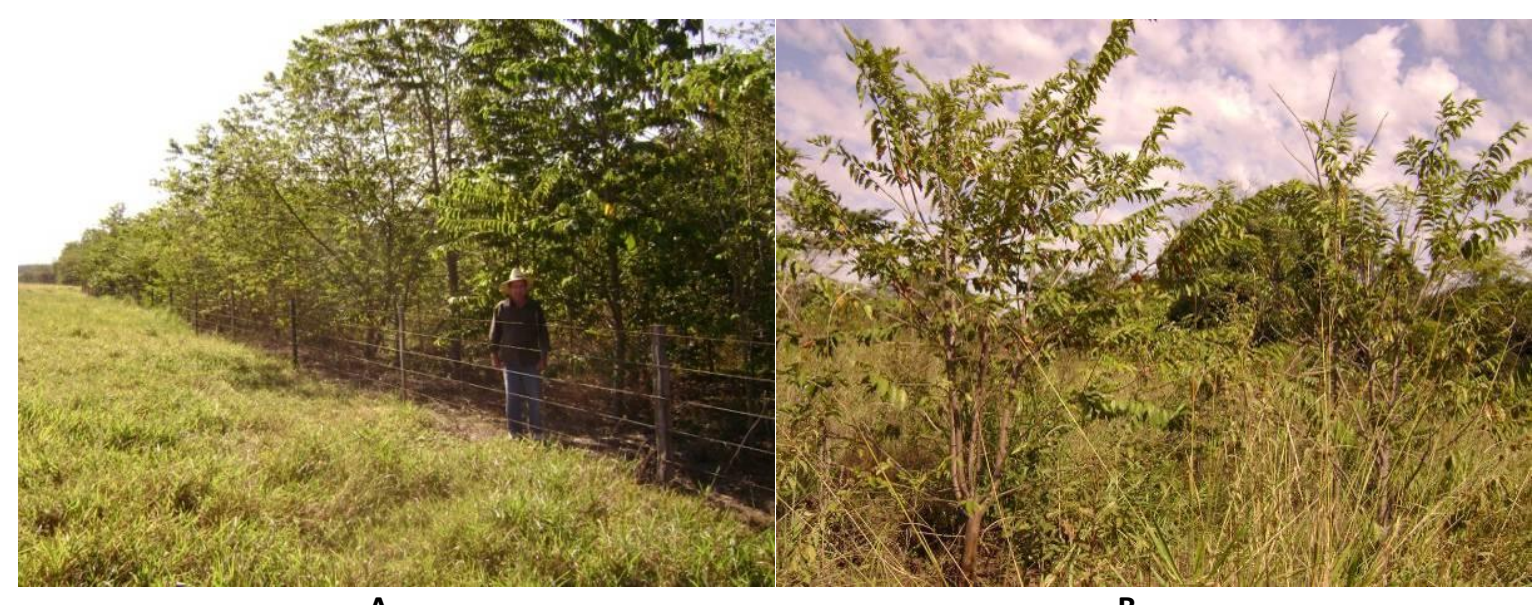

A

B

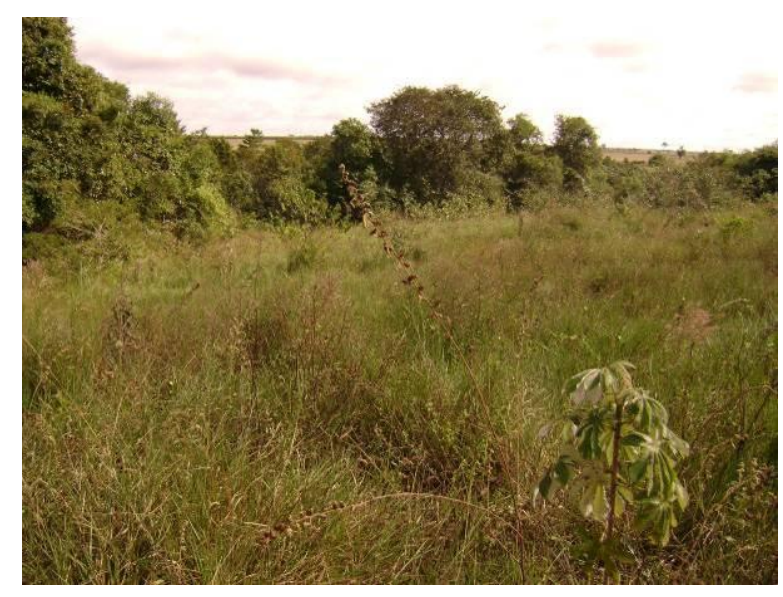

C

Figura 2. Projetos de reflorestamento ciliar através do Programa de Fomento Florestal no córrego do Galante: (A) projeto formado; (B) projeto parcialmente formado e $(C)$ projeto não formado.

\section{CONSIDERAÇÕES FINAIS.}




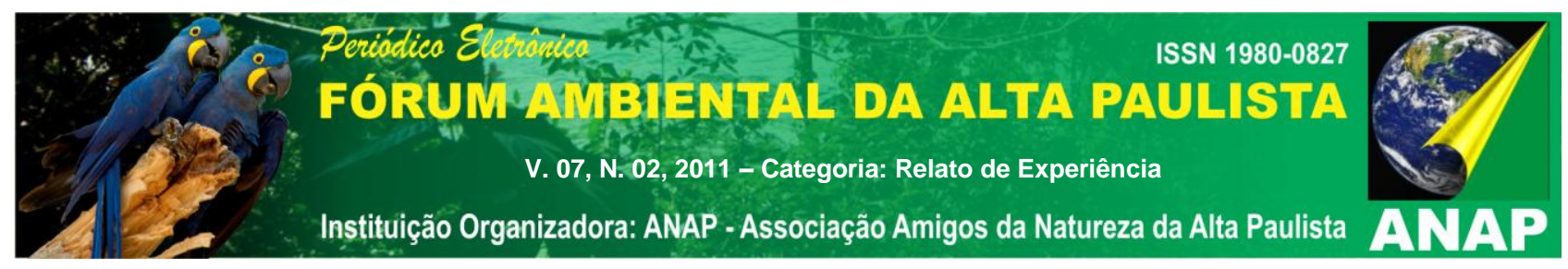

O êxito dessa parceria será importante para fomentar novas experiências para recuperação de Áreas de Preservação Permanente que se encontram degradadas na região.

A CESP ganha com a conservação dos recursos hídricos, matéria-prima para a produção de energia hidrelétrica, e exercita sua responsabilidade ambiental nas áreas de influência de seus empreendimentos. Para os proprietários os ganhos são a conformidade legal, a beleza cênica e a valorização de suas propriedades e de seus produtos, em um mercado cada vez mais exigente quanto à sustentabilidade ambiental.

\section{REFERÊNCIAS}

CESP. Recuperação de áreas degradadas. 2 Ed. São Paulo: CESP ( Série Pesquisa e Desenvolvimento, 059). São Paulo, 1992. 12p.

KAGEYAMA, P. Y. Recomposição da vegetação com espécies arbóreas nativas em reservatórios de usinas hidrelétricas da CESP. Série Técnica IPEF, v.8, n.25. Piracicaba, 1992. p. 1-43.

KAGEYAMA, P. Y., CASTRO, C.F.A. Sucessão secundária, estrutura genética e plantações de espécies arbóreas nativas. In SIMPÓSIO INTERNACIONAL SOBRE ALTERNATIVAS PARA O DESMATAMENTO NA AMAZÔNICA. Anais. Belém, 1988. p. 135.

MARTINS, P.S. Preservação e genética. In ENCONTRO SOBRE RECURSOS GENÉTICOS. Anais. Jaboticabal, 1988. p. 62-66. 


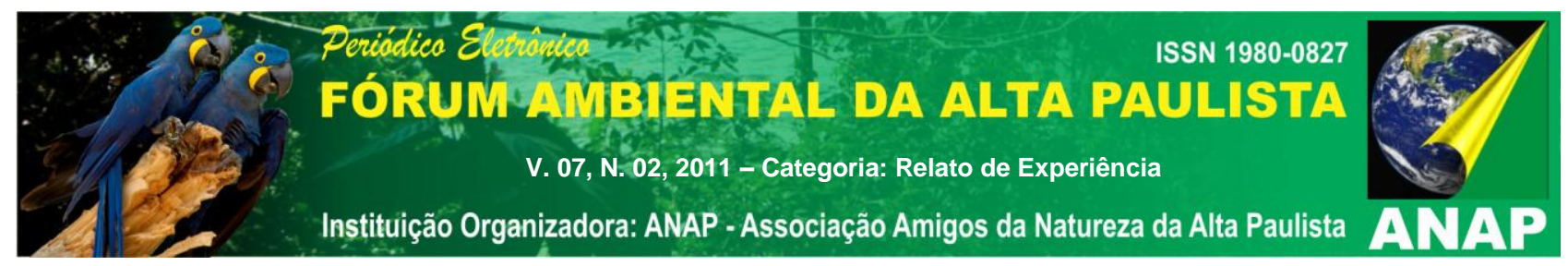

